\title{
Memória institucional por meio da organização documental de fotografias
}

\author{
Institutional memory through documentary organization of pictures
}

\begin{abstract}
Roseane Souza de Mendonça
Mestre em Ciência da Informação pela Universidade Federal de Pernambuco - UFPE. Bibliotecária no Centro Acadêmico de Vitória de Santo Antão da UFPE. E-mail: roseane.photo@gmail.com

Fabio Assis Pinho

Doutor em Ciência da Informação pela UNESP, campus de Marília. Professor no Departamento de Ciência da Informação da UFPE. ORCID ID: http://orcid.org/0000-0003-1346-3808

E-mail: fabiopinho@ufpe.br
\end{abstract}

\begin{abstract}
Resumo
Este artigo é resultado de uma pesquisa cujo tema foi imagem e palavra se articulando à memória institucional, que impõe uma reflexão sobre os elementos que constituem a organização da informação. Realizou-se uma pesquisa exploratória, de procedimento documental, com revisão de literatura abrangendo as dimensões teóricoconceituais da Organização da Informação e do Conhecimento e da Memória. Por isso, objetivou-se propor estratégias de organização do acervo fotográfico digital do Centro Acadêmico de Vitória de Santo Antão (CAV) da Universidade Federal de Pernambuco (UFPE), com o intuito de reconstrução da memória institucional. Do ponto de vista metodológico, no que tange à reunião das imagens fotográficas, trabalhou-se com acervo fotográfico constituído no período de 2010-2014. As fotografias foram descritas utilizando-se de campos do MARC 21, acrescentando-se narrativas a cada fotografia, além disso, criaram-se categorias pautadas na Análise Documental e, por fim, foi utilizado o DSpace para o armazenamento dos registros. Concluiu-se que a narrativa abre diversas possibilidades na organização documental visando ao fazer memorial, e que é necessária certa flexibilização nos sistemas de informação para compreender os processos interpretativos.
\end{abstract}

Palavras-chave: Memória Institucional. Organização da Informação. Organização do Conhecimento. Narrativa. MARC21. Fotografia.

\begin{abstract}
This paper resulted from a survey with the theme image and word articulating with institutional memory, which requires a reflection on the elements of the information organization. We conducted an exploratory research, document procedure, with literature review covering the theoretical and conceptual dimensions of the Information and Knowledge Organization and Memory. Therefore, the aim was to propose organizing strategies of digital photographic collection of the Academic Center of Vitória de Santo Antão (CAV) of the Federal University of Pernambuco (UFPE), with the aim of rebuilding institutional memory. From a methodological point of view, regarding the meeting of the photographic images, we worked with photographic collection made in 2010-2014 period. The photographs were described using the MARC 21 fields by including narratives to each photo also guided categories were created in Documentary Analysis and was used DSpace for storage of records. It was concluded that the narrative opens several possibilities in the documentary organization aiming to make memorial, which is required certain flexibility in information systems to understand the interpretative processes.
\end{abstract}

Keywords: Institutional memory. Information organization. Knowledge organization. Narrative. MARC21. Photography.

InCID: R. Ci. Inf. e Doc., Ribeirão Preto, v. 7, n. 1, p. 90-110, mar./ago. 2016.

DOI: 10.11606/issn.2178-2075.v7i1p90-110 


\section{Introdução}

A crise no ensino superior do Brasil se acentuou a partir dos anos 1990 provocando o início de sérias discussões para a criação de um plano de ação visando à reestruturação, ao desenvolvimento e à democratização das Instituições Federais de Ensino Superior (IFES). Isso provocou a interiorização do ensino superior no Estado de Pernambuco e possibilitou a criação dos campi da Universidade Federal de Pernambuco (UFPE) nas cidades de Caruaru, Vitória de Santo Antão, Garanhuns, Serra Talhada e Petrolina.

A chegada da universidade pública ao interior pernambucano criou expectativas no sentido de reduzir as desigualdades sociais por meio do ensino superior e também de promover uma alavancada na dinâmica da economia local. Como uma instituição social, a universidade é detentora de uma produção intelectual produzida por seus integrantes e a seu respeito, que precisa ser preservada, pois se constitui em patrimônio da sociedade. Esse movimento de preservação inclui a memória institucional que deve servir para atestar as transformações, revisar a história e prestar contas do investimento realizado para uma educação pública de qualidade.

Informação, Fotografia, Narrativa e Memória são os alicerces dessa pesquisa, pois se acredita que o estudo desses elementos pode contribuir para o processo do que deve se tornar memorável em âmbito institucional, a partir da apreensão do conhecimento produzido e sua organização e disponibilização para a sociedade.

A Ciência da Informação (CI), por se constituir no campo das ciências modernas que busca entender o fenômeno informação, possui caráter transdisciplinar, e se encontra sob a égide de vários olhares, o que incide em um caminho de mão dupla: dificulta especificar seu objeto de estudo (a informação), mas permite transitar por diferentes áreas do conhecimento e inserir contribuições das mais diversas ordens, uma vez que a informação é a base do conhecimento humano. Essa informação está no cerne da sociedade atuando em todos os setores (econômico, social, cultural, científico etc.), constituindo-se em um bem público que se transforma em conhecimento.

O conhecimento aqui defendido é aquele efetivado pela permanente troca e circulação de informação; ele é fruto de um sistema de habilidades interconectadas, que Gardner (1994) chamou de "inteligências". O estudo do conhecimento remonta aos filósofos gregos que o entenderam como fundamental para a compreensão da própria razão humana. (CHAUí, 2009). 
O processo de aquisição do conhecimento é reflexo das percepções sensoriais que induzem às reflexões, que passam a ser registradas em documento escrito ou em meio digital, e se tornam acessíveis aos indivíduos que internalizam o conhecimento de coisas e eventos. A informação ao se transformar em conhecimento é solidificada na mente como forma de distinção entre razão e emoção. Como se pode entender, o conhecimento exige mais que apenas obter uma informação, um dado, é necessário estabelecer correlações.

De natureza plurissignificativa e subjetiva, a informação tem seu conceito geralmente atrelado ao seu uso. Neste estudo se compactua com Le Coadic (2004, p.4) ao se centralizar no conceito de informação que está relacionado com a cognição e a comunicação humanas, definindo a informação como "um conhecimento inscrito (registrado) em forma escrita (impressa ou digital), oral ou audiovisual, em um suporte", sem deixar de acreditar que esta informação deve ser elo entre o produto e o processo de reflexão (CARDOSO, 1994).

Vale ressaltar, que não se trata apenas de se deter no significado do termo informação, mas, como este se relaciona a outros termos básicos como documentos, textos e conhecimento (CAPURRO; HJORLAND, 2007), compreendendo que se trata de um processo de produção de sentido, que envolve, dentre outras coisas, comunicação e concepção de mundo.

No que concerne à comunicação humana e seu processo, tem-se a linguagem como intermediadora entre os seres e o mundo, relacionando-os. As linguagens oral, verbal ou visual são processos de representação utilizados pelo ser humano que estabelecem uma comunicação consistente e eficaz, seja no âmbito social ou organizacional. A comunicação possibilita ao homem conhecer, apreender, difundir e adquirir conhecimento; ela vem sofrendo transformações em virtude das mudanças advindas da modernização da vida, sendo boa parte dessas modificações consequência das inovações tecnológicas, inovações estas que modificam o poder narrativo, o uso da fotografia e a concepção de memória.

Nesse processo de comunicação se encontra a narrativa, que é uma atividade humana no uso da linguagem; ela mostra por diferentes maneiras como o ser humano experiência o mundo. Não consiste em simples relato, em contar uma história, ela está permeada de um sentido social e histórico e tem uma relação com o tempo e o espaço, sendo também uma forma de identidade, de pertencimento. A narrativa se ocupa em traduzir o saber para o contar, ela é a expressão dos momentos de importância que fazem parte da memória cultural e individual, que permeia o discurso cotidiano, também pode ser reservada para momentos especiais, marcado 
por contextos específicos onde os membros de um grupo se juntam para se divertirem e se comunicarem. (LANGDON, 1999).

Nesse contexto, a fotografia pode ser utilizada como documento e dispositivo que ativa a memória ao trazer ao espectador um novo conhecimento quando ouve um relato de vida, ao possibilitar (re)viver histórias e até conseguir inserir-se no ambiente narrado.

No seu sentido histórico, a narrativa se aproxima da memória que, para se diferenciar da história foi, definida por Platão como um bloco de cera onde as impressões ficam gravadas, bastando evocá-las quando fosse necessário; e que Pollak (1992) considerou intercambiável entre o individual e coletivo, caracterizando-se pela seletividade; tratando-se, assim, do que Holanda (2012) chama de multiplicidade e permanência, denominando-a simultaneamente individual e pública nesse mundo digital.

Estabelecendo semelhanças, pode-se pensar que a memória é um grande armazém onde se dispõe de ferramentas e insumos para a construção e manutenção de uma edificação. Esse espaço é construído e desconstruído permanentemente e nele habitam seres vivos. O ser organizacional é antes de tudo o ser social que está carregado de conceitos, pré-conceitos, vivências e lembranças. Esse panorama está diretamente ligado à maneira como esse ser adquire, assimila, retém, exclui e utiliza a informação. A memória é basicamente isso: informação que transita, que fica retida, que é excluída e/ou armazenada; em termos mais complexos ela está envolvida em questões cognitivas, fisiológicas, sociológicas, pessoais, políticas e institucionais. Muito do que se internaliza como memória é fruto da narrativa que faz parte da linguagem humana e se constitui em meio de comunicação desde os primórdios, e assim se compõe essa pesquisa: da reunião entre imagem e palavra se articula uma memória coletiva e possivelmente institucional, e um repensar a respeito da configuração da representação do conhecimento em Sistemas de Informação universitários.

Estabelecer o que será a memória institucional não se constitui em tarefa fácil, essa atividade complexa exige que haja uma metodologia o mais completa possível e que não apresente tendências, ou seja, não reflita valores políticos e pessoais, contudo, seja capaz de atender aos anseios dos consulentes. Afinal,

As instituições quando expõem a sua memória têm a oportunidade de resgatar sua imagem perante a comunidade, notadamente como é o caso de instituições de ensino, que sempre trazem grandes impactos para as sociedades nas quais estão inseridas. (MORENO; LOPES; DI CHIARA, 2011, p. 4). 
O reconhecimento da importância da existência de uma instituição deve refletir-se na preservação de sua história, ou seja, de seus valores, de sua identidade e do saber acumulado. Para Thiesen (2013), o conceito de memória institucional não é simples, antes é preciso estabelecer as diferenças entre organização e instituição e buscar entendimento do processo de institucionalização das relações sociais porque as instituições são feitas de práticas sociais que não podem ser ignoradas. Para ela, o importante na formação do conceito de memória institucional é poder perceber os aspectos instituintes e o caráter formalizador de realidades.

Essas considerações sobre instituição implicam diretamente na escolha do material a ser arquivado, nas diretrizes a serem definidas para essas escolhas, na transparência de informações, no trabalho conjunto com uma equipe multidisciplinar, bem como se está imbuído da realidade afetiva e social do local.

Vale ressaltar, que, ao discorrer sobre memória, convive-se com as abordagens filosóficas, psicológicas e históricas, dentre outras. Isso ocorre como resultado da demanda de conhecimento da sociedade, que sempre buscou salvaguardar sua história desde tempos remotos, a princípio de forma oral, atualmente no ciberespaço, onde a matéria-prima mais importante sempre foi e continua sendo a informação.

Nesse sentido, parte-se para um desafio de um novo olhar sobre os elementos da Organização e Representação da Informação e do Conhecimento a fim de (re)construir a memória, que traz aspectos da lembrança, que ratifica informações, que ressignifica momentos e narra a existência que se deu em um determinado momento. Intenta-se uma reflexão sobre a inserção da narrativa no fazer memorial sob os olhos da CI, dando vazão ao desafio que Capurro e Hjorland (2007, p. 194) evidenciam quanto à “(...) CI ser mais receptiva aos impactos sociais e culturais dos processos interpretativos e, também, às diferenças qualitativas entre diferentes contextos e mídias".

A representação da informação e do conhecimento, na atualidade, está em um universo multifacetado, regido por tecnologias da informação e comunicação, onde é preciso encontrar novos sentidos e novas práticas diante da larga escala de produção e disseminação da informação. Nesse cenário se encontram as bibliotecas, arquivos, museus e outros tipos de instituições de memória, bem como os profissionais da informação, que precisam atualizar técnicas para contribuir com a criação de Sistemas de Informação eficazes e eficientes. Isso perpassa por um sistema bem estruturado, que permite a inclusão de qualquer tipo de documento (oral, escrito, visual etc.) e possibilite o acesso e a recuperação da informação de 
forma a satisfazer seus usuários. Também se faz necessária a aquisição de novos conhecimentos, não apenas sobre lidar com tecnologias, mas sobre a própria informação em si.

Nessas circunstâncias a presente pesquisa está incluída na temática que norteia as dimensões teórico-conceituais da Organização da Informação e do Conhecimento. O objeto de estudo é a organização da informação como meio para a composição da Memória Institucional do Centro Acadêmico de Vitória de Santo Antão (CAV) da Universidade Federal de Pernambuco (UFPE), partindo-se da hipótese de que a fotografia e a narrativa são elementos constituintes da memória individual e coletiva. Por isso, propõe-se colaborar para a preservação da memória enfatizando a narrativa e o valor documental das fotografias, logo, buscando-se responder ao seguinte questionamento: como a organização documental das fotografias do Centro Acadêmico de Vitória de Santo Antão (CAV), da Universidade Federal de Pernambuco (UFPE), pode contribuir para a sua memória institucional?

A resposta para essa questão de pesquisa está inserida em uma vertente da CI que se fundamenta em uma concepção de informação como processo de construção do conhecimento, apoiada na cultura e nas práticas sociais, mantendo diálogo com diversas áreas do conhecimento por sua característica transdisciplinar. Nesse sentido, é inegável que o visual tem assumido papel de destaque na sociedade. A fotografia largamente difundida faz a humanidade viver hoje as mais diversas experiências por meio da imagem. Nesse contexto, objetivou-se, em âmbito geral, propor estratégias de organização do acervo fotográfico digital do CAV para fins de construção da memória institucional. 


\section{Morar no interior do meu interior: fragmentos sobre a interiorização do Ensino Superior}

A universidade tem sido o espaço de cultivo e transmissão do saber humano acumulado, um lugar de importante desenvolvimento intelectual. É neste espaço que se constitui o campo de atuação desta pesquisa; portanto, nesta seção se apresenta um pouco da UFPE, da sua chegada ao interior, da cidade de Vitória de Santo Antão e do Centro Acadêmico ali instalado.

Do latim universitate, a universidade significa universalidade, totalidade, conjunto; corpo, companhia, corporação, comunidade (UNIVERSIDADE, 2013). Historicamente ela vai se transformando e se adequando à nova realidade; contudo, mantém tradicionalmente os traços que a idealizaram, que são comunidade, imunidade e universalidade. Sua herança do mundo greco-romano vai aos poucos "assumindo uma forma específica no contexto religioso do Oriente islâmico e do Ocidente cristão" (WANDERLEY, 1994, p. 15).

A princípio foi criada para formar uma elite aristocrática, mas a revolução industrial impôs "exigências de especializações e técnicas que se [ajustassem] à nova divisão social do trabalho" como reflexo do modo de produção capitalista. (WANDERLEY, 1994, p. 18). É a partir daí que se busca a integração entre o ensino e a pesquisa na tarefa de se adequar aos processos de desenvolvimento econômico e social conforme as características de cada país. Neste momento, a universidade deixa de ser o celeiro da burguesia, com intuito de acesso aos postos políticos e burocráticos, e passa a atender às reivindicações de mobilidade social dos filhos da classe média.

É nessa ideia de conjunto e comunidade que nasce a Universidade do Recife (UR), sendo fruto da união das Faculdades de Direito, Medicina e Filosofia, juntamente com as Escolas de Engenharia, Belas Artes, Farmácia e Odontologia (BERNARDES; PEREIRA, 2011). A então UR foi instituída pelo Decreto ${ }^{\circ} 9.388$ de 20 de junho 1946 que a declarou criada, sendo uma “instituição de ensino superior, como pessoa jurídica, dotada de autonomia administrativa, financeira, didática e disciplinar, nos termos da legislação federal e do Estatuto, que a [regulamenta]" (BRASIL, 1946). Porém, só após 20 anos é que ela é vinculada ao Ministério da Educação (MEC) tornando-se a UFPE.

Figurando entre uma das melhores Universidades do Brasil, a UFPE tem por missão: "Promover um ambiente adequado ao desenvolvimento de pessoas e à construção de conhecimentos e competências que contribuam para a sustentabilidade da sociedade, através do

InCID: R. Ci. Inf. e Doc., Ribeirão Preto, v. 7, n. 1, p. 90-110, mar./ago. 2016. 


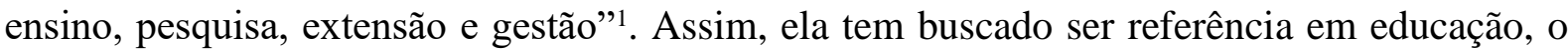
que naturalmente a insere no contexto político, histórico e social de Pernambuco.

Com relevante atuação no ensino (graduação e pós-graduação) e na pesquisa, a UFPE tem também respondido ao pleito da população ampliando sua interação social e respondendo ao desenvolvimento do Estado. Disso decorrem a criação de novos cursos, o aumento das vagas em cursos já existentes, implantação da Educação a distância (EaD), além de manter foco no cenário econômico do Estado oferecendo oportunidades de ensino conforme demanda. Esse crescimento é consequência de dois programas do MEC, que são o de Interiorização do Ensino Superior e o de Apoio a Planos de Reestruturação e Expansão das Universidades Federais (Reuni).

O Reuni é fruto das discussões iniciadas com a acentuação da crise no ensino superior do Brasil nos anos 1990 e se constitui em um plano de ação visando à reestruturação, ao desenvolvimento e à democratização das IFES, implementado pelo Decreto no 6.096 de 24 de abril de 2007. Seu objetivo é de ampliar o acesso e permanência no ensino superior, estabelecendo uma meta para dez anos (a partir de 2008) com o intuito de dobrar o número de alunos na graduação. Isso implica na flexibilização de currículos, no combate à evasão, no aumento de vagas, na criação de novos cursos e na contratação de professores e técnicos, tudo isso a fim de diminuir as desigualdades sociais no país.

O programa de Interiorização do Ensino Superior possibilitou ao Estado de Pernambuco contar com a criação dos campi da UFPE nas cidades de Caruaru e Vitória de Santo Antão, assim como a Universidade Federal Rural de Pernambuco (UFRPE) chegar às cidades de Garanhuns, Serra Talhada e Petrolina.

Almeja-se que, com a chegada da universidade pública ao interior de Pernambuco, haja redução das desigualdades sociais e uma alavancada na dinâmica econômica local. É aceitável essa expectativa porque é na universidade federal que o povo quer ver aplicados os investimentos públicos, afinal, é ela que forma a maioria dos quadros profissionais e onde são desenvolvidas pesquisas que beneficiam a indústria, a agricultura e a economia de forma geral.

O novo dialoga constantemente com a tradição. Compreender os desafios de implantação de um campus no interior do Estado, assim como a formação do corpo docente e

\footnotetext{
${ }^{1}$ Disponível em:

$\langle$ http://www.ufpe.br/ufpenova/index.php?option=com_content\&view=article\&id=56\&Itemid=260>. Acesso em: 12 mar. 2016.
}

InCID: R. Ci. Inf. e Doc., Ribeirão Preto, v. 7, n. 1, p. 90-110, mar./ago. 2016. 
discente, a construção de prédios, o planejamento e definição de diretrizes para funcionamento são alguns dos modos de contribuir para consolidar a história e construir pouco a pouco uma memória que possa servir de referência a futuras consultas e como testamento de um tempo.

\section{A cidade de Vitória de Santo Antão (PE)}

Com uma população contabilizada pelo censo 2010, conforme o Instituto Brasileiro de Geografia e Estatística (IBGE)², em 129.974 habitantes e uma estimativa para 2014 de 134.871 habitantes, Vitória de Santo Antão é um município que está localizado na Zona da Mata do Estado de Pernambuco, com uma área territorial de $372,637 \mathrm{~km}^{2}$ numa região em franca expansão industrial e econômica.

O Distrito de Vitória de Santo Antão foi criado por alvará de 14 de março de 1783 e pela Lei Municipal nº192, de 16 de maio de 1914. Seu povoamento data da primeira metade do século XVII com a chegada do português Diogo Braga, da ilha de Santo Antão, do arquipélago de Cabo Verde, em 1626. Ele se estabeleceu com a família e os seus agregados para se dedicar às atividades agropastoris, quando adquiriu fazendas e construiu sua residência e uma capela, esta consagrada a Santo Antão, padroeiro da ilha e protetor contra roubo de gado. Nas proximidades da capela, cresceu um povoado conhecido por cidade do Braga, posteriormente denominado Santo Antão da Mata, designação da primitiva casa de oração e antiga mata ali existente. Em 1645, a nove quilômetros de Santo Antão da Mata, travou-se a batalha do monte das Tabocas, contra os holandeses. Em 1710, por ocasião da Guerra dos Mascates, o povoado foi ameaçado, mas a tropa legalista se negou a combater, apoiando os rebeldes e aprisionando o comandante. Em 1783, foi criado o Distrito com topônimo Vitória de Santo Antão, lembrando o sucesso dos pernambucanos na batalha dos montes das Tabocas e em 1811, passou à categoria de município. ${ }^{3}$

\footnotetext{
${ }^{2}$ Disponível em: <http://cidades.ibge.gov.br/xtras/perfil.php?lang=\&codmun=261640\&search=pernambuco|vitoria-de-santoantao $\rangle$. Acesso em: 12 mar. 2016.

${ }^{3}$ Disponível em:

<http://www.cidades.ibge.gov.br/painel/historico.php?lang=\&codmun=261640\&search=\|infogr\%E1ficos:hist\%F3rico>. Acesso em: 12 mar. 2016.

InCID: R. Ci. Inf. e Doc., Ribeirão Preto, v. 7, n. 1, p. 90-110, mar./ago. 2016.
} 


\section{O Centro Acadêmico de Vitória de Santo Antão (CAV)}

O CAV nasceu da determinação do Governo Federal de interiorizar a educação superior pública. Constitui-se em um dos campi da UFPE, localizado na cidade de Vitória de Santo Antão, que está a 50 km do Recife. Teve sua inauguração em 21 de agosto de 2006 e segue o Regimento e o Estatuto da UFPE.

As primeiras instalações foram iniciadas em terreno doado pela Prefeitura da cidade, localizado no Alto do Reservatório, que abriga um prédio construído em 1912, onde outrora funcionou a Escola de Economia Doméstica Rural, denominada atualmente Instituto Federal de Educação Tecnológica (IFPE) - Campus Vitória. Na época, a administração municipal por meio da Lei n. 446, de 27 de janeiro de 1954, doou o prédio construído em 1912 no sítio Boa Vista (Alto do Reservatório) para a instalação da Escola. Segundo narrativas de alguns pesquisadores locais, o prédio quando foi criado em 1912 funcionava como hospital e recebia as pessoas doentes com peste e outras doenças contagiosas (ARAGÃO, 1983).

O Centro começou suas atividades com três cursos, a saber: Ciências Biológicas, Enfermagem e Nutrição, oferecendo respectivamente 60, 35 e 30 vagas. Em 2014, aos oito anos de atividades, o CAV possui em sua estrutura os cursos de graduação em Ciências Biológicas (Licenciatura), Enfermagem, Nutrição (Bacharelado), Educação Física (Licenciatura e Bacharelado) e Saúde Coletiva. Na Pós-graduação são oferecidos os Mestrados em Saúde Humana e Meio Ambiente, Nutrição, Atividade Física e Plasticidade Fenotípica, bem como o

Programa de Residência Multiprofissional em Saúde da Família e a Residência Multiprofissional de Interiorização de Atenção à Saúde. 


\section{A fotografia como instrumento de memória}

Pode-se projetar um mundo sem imagens? Provavelmente não, afinal, mesmo que o ser humano esteja privado de sua visão, ainda assim, ele conseguirá elaborar imagens mentais. É o que Santaella e Nöth (2010) chamam de domínio imaterial (imagens na nossa mente), onde as imagens aparecem como visões, fantasias, imaginações, esquemas, modelos ou, em geral, como representações mentais a fim de representar, informar, direcionar o indivíduo. "A imagem mental é construída por todos nossos mecanismos perceptivos, assim como as outras percepções são também interfaces de um processo de conhecimento" (TACCA, 2005, p.12).

Nesse âmbito está a fotografia, que, na tentativa de congelar o tempo, permeia o cotidiano do ser humano como forma de distingui-lo no mundo, constituindo-se numa linguagem de representação plástica universal. Nesta seção se esclarece seu uso como fonte de informação, configurado no documento fotográfico, objeto da organização e representação da informação e do conhecimento e passível de descrição e como construtor de memória, tanto social como institucional.

Surgida na primeira metade do séc. XIX, em 1839, a fotografia inaugura um novo modo de apreciar a sociedade; traz consigo uma riqueza de detalhes até então não percebida por meio da pintura. É necessário esclarecer que mesmo antes da escrita, que tornou linear o registro da história do mundo, os homens encontraram na produção de imagens ${ }^{4}$ uma forma de guardar momentos, contar histórias, trocar informações e ideias, sendo as imagens elementos capazes de representar o mundo real ${ }^{5}$ graças à capacidade imaginativa de quem as concebe e a consome como espectador. A imagem é uma das mais antigas formas de registro da humanidade, que remete às pinturas rupestres de mais de 20 mil anos, quando os homens registravam sua vida nas paredes das cavernas.

Desde a terceira década do século XIX a fotografia é considerada uma das principais fontes documentais da história. As coleções de fotografia vão se constituindo como rica fonte de ensinamentos que englobam uma diversidade de técnicas e contam a própria História da Fotografia. Sua evolução técnica se constitui de vários processos fotográficos, aqui entendidos

\footnotetext{
${ }^{4}$ Entenda-se aqui o conceito de imagem definido por Smit (1996, p. 29) em que "abrange um vasto leque de documentos iconográficos ou de ilustrações, incluindo pinturas, gravuras, posters, cartões postais, fotografias, etc."

${ }^{5}$ No Brasil, a ocupação holandesa que se deu em 1624, trouxe na corte de Maurício de Nassau, pintores, arquitetos, cartógrafos, naturalistas etc. para registro do Novo Mundo, demonstrando a preocupação com a inscrição do que se encontrara. (BRIENEN, 2010).
}

InCID: R. Ci. Inf. e Doc., Ribeirão Preto, v. 7, n. 1, p. 90-110, mar./ago. 2016. 
como "o conjunto de procedimentos e processos químicos e fotoquímicos que conduzem à obtenção de uma fotografia" (PAVÃO, 1997, p. 25).

A priori ela se constitui em um "elemento de identidade visual e um acesso para ver-se (sic) a si próprio, a fundação das individualidades ao manter consigo uma imagem de pessoa querida (...)" (TACCA, 2005). Posteriormente, foi sendo utilizada gradativamente para fins científicos (como nos retratos do século XIX) e como registro etnográfico do homem. No entanto, a fotografia não é fruto de inspiração artística, nasce atrelada a uma técnica, fruto de uma nova forma de pensar e agir. Inicia-se numa sociedade recém-saída da revolução industrial, que está se modificando econômica e socialmente. Contudo é, antes de qualquer valor sociocultural, estético, filosófico, entre outros, um processo físico-químico, de caráter mecânico, alicerçado no tripé: luz, suporte e formato.

Com a revolução industrial a fotografia passou a ser fundamental como fonte de informação6 e conhecimento, ou seja, "teria papel fundamental enquanto possibilidade inovadora de informação e conhecimento, instrumento de apoio à pesquisa em diferentes campos da ciência (...)" (KOSSOY, 2001, p. 25). Assim, o homem, que até então conhecia outros mundos por meio da expressão escrita, verbal e pictórica, passou a contar com essa nova ferramenta que permitiu um conhecimento preciso e amplo de outras realidades. (KOSSOY, 2001).

É na década de 1980 que aumenta o interesse pela fotografia como fonte de pesquisa e se começa a verificar os recursos potenciais da leitura das imagens. Em sua gênese a fotografia está ligada à literatura e à comunicação, evidenciando implicitamente a narrativa. Esclarecenos este fato Bauret quando explica os discursos referentes à fotografia, a saber:

\begin{abstract}
Além do discurso estético, que, no mundo da fotografia, tende a privilegiar qualquer manifestação de carácter criativo e a constituir um estudo das formas e da sua evolução, ligando-as a diferentes tradições visuais como a do enquadramento, uma sociologia da fotografia assenta sobre um estudo sistemático dos diferentes contextos desta prática; quanto à semiologia, permitiu tomar em consideração a imagem fotográfica como mensagem, desmontando o processo da sua comunicação, e, em particular, os diferentes tipos de códigos. Mas, tal como qualquer outra forma de arte e de literatura, tal como qualquer texto, a imagem fotográfica só existe plenamente se for fruída por um leitor que lhe dê uma interpretação. (BAURET, 2010, p. 11, grifo nosso).
\end{abstract}

Ao longo de dois séculos de existência a fotografia sofre mudanças substanciais em seus paradigmas. O fascínio pela imagem pode se dar em razão de ser a visão uma atividade

\footnotetext{
${ }^{6} \mathrm{Na}$ semiótica, tudo pode transmitir informação, uma vez que todas as coisas são interpretadas como um signo de outra coisa (GNOLI, 2012).
}

InCID: R. Ci. Inf. e Doc., Ribeirão Preto, v. 7, n. 1, p. 90-110, mar./ago. 2016. 
complexa que não pode ser dissociada das grandes funções psíquicas (AUMONT, 2008). O ato de ver antecede ao de falar e andar, o que pressupõe o valor que a imagem transmite ao homem. Explica-se isso, em parte, pela verossimilhança que a máquina tem com o olho humano, servindo como auxiliar para a percepção do indivíduo.

No campo da documentação, Paul Otlet, em 1934, já ampliava a ideia de documento para além dos livros, e classificava a fotografia considerando-a "a mais importante forma de representação gráfica da documentação" (BUCCERONI; PINHEIRO, 2009, p. 130).

No contexto da CI a fotografia tem sido analisada como "documento e informação no âmbito da representação e recuperação da informação fotográfica e de soluções de arquivamento e preservação" (BUCCERONI; PINHEIRO, 2009, p. 129). É nessa condição de documento, portadora de informação, que a fotografia é trabalhada pela Organização e Representação da Informação e do Conhecimento, que atua numa perspectiva pragmática sóciocognitiva preocupando-se com o uso da informação em diferentes suportes.

\section{Organização Documental das Fotografias do CAV}

A presente pesquisa se utilizou de elementos da Organização e Representação da Informação e do Conhecimento como meio para a composição da memória institucional, partindo-se da hipótese de que a fotografia e a narrativa são elementos constituintes dessa composição. Designou-se como exploratória ao buscar aprimorar ideias e proporcionar visão geral e maior familiaridade com determinado fato, na intenção de torná-lo explícito. De planejamento mais flexível, normalmente esse tipo de pesquisa envolve levantamento bibliográfico, entrevistas não padronizadas e análise de exemplos (GIL, 2008). De procedimento bibliográfico e documental, a pesquisa bibliográfica foi efetivada por meio de relatórios anuais do $\mathrm{CAV}$, conversa informal com egressos e funcionários, reportagens em jornais, fotografias, assim como consulta a livros, periódicos, anais, dissertações e teses de autores da CI (com foco na organização da informação e do conhecimento), da fotografia, da narrativa e da memória a fim de se aproximar do tema, e delinear a estrutura teórica que encadeia a pesquisa.

$\mathrm{Na}$ etapa seguinte, para reunião das fotografias, buscou-se sensibilizar a comunidade universitária para que participassem enviando fotos que fossem concernentes ao CAV e tudo que pudesse refletir como memória desde sua implantação em 2006. Para tanto, foi utilizado o

InCID: R. Ci. Inf. e Doc., Ribeirão Preto, v. 7, n. 1, p. 90-110, mar./ago. 2016. 
canal de comunicação já praticado pelo Centro que dá ampla ciência de tudo que envolve a administração geral e gestão de pessoas, que é a mala direta. Por essa via foi repassado o Termo de Consentimento Livre e Esclarecido (TCLE) da pesquisa, procedendo à solicitação de envio das fotografias para um e-mail específico.

Diante desse panorama, optou-se por utilizar para análise 1.420 fotografias digitais no período de 2010 a 2014. Destas, 150 foram selecionadas e 91 classificadas e utilizadas como referência para análise, constituindo-se assim no corpus desta pesquisa. As fotos foram selecionadas em função de seu valor como documentos que retratam aspectos importantes da trajetória da instituição e de seus personagens. Em sua maioria versam sobre o espaço físico, reformas, prédios, eventos comemorativos como confraternizações, visitas de políticos, retratos, atividades como treinamentos etc. Essa amostragem por acessibilidade ou por conveniência é isenta de rigor estatístico, sendo utilizada em pesquisas exploratórias onde "o pesquisador seleciona os elementos a que tem acesso, admitindo que estes possam, de alguma forma, representar o universo" (GIL, 2008, p. 94).

As imagens reunidas estão organizadas em computador e em HD externo por pastas. Uma pasta geral corresponde ao ano, dentro desta há uma subpasta com cada evento fotografado e respectiva data no formato: AAAA_MM_DD e nome do evento (ano completo, mês e dia). Por exemplo: Pasta 2011 - subpasta 2011_08_30Missa_5anos_CAV, conforme a categorização elas passam para a pasta correspondente. Por isso, após cuidadosa análise das fotografias partiuse para a etapa de criação das categorias.

Essa etapa se valeu da Análise Documental (AD), da tematização e da técnica de observação das atividades e do ambiente onde se desenvolve a pesquisa, perfeitamente aceitável em estudos exploratórios conforme Gil (2008). A observação direta, segundo Richardson (2012, p. 259), “sob algum aspecto, é imprescindível em qualquer processo de pesquisa científica, pois ela tanto pode conjugar-se (sic) a outras técnicas de coleta de dados como pode ser empregada de forma independente e/ ou exclusiva".

Na criação das categorias, apesar de não se trabalhar com Análise de Conteúdo - o que se pretende posteriormente como extensão dessa pesquisa considera-se esclarecedor o que recomenda Bardin (2011) quanto à qualidade das categorias, que são: Exclusão mútua - cada elemento só pode estar em uma categoria; Homogeneidade - para definir uma categoria, é preciso haver um único princípio ou critério de classificação; Pertinência - as categorias devem dizer respeito às intenções do investigador, aos objetivos da pesquisa às questões norteadoras, 
às características da mensagem etc.; Objetividade e Fidelidade - se as categorias forem bem definidas, se os índices e indicadores que determinam a entrada de um elemento em uma categoria forem bem claros, não haverá distorções devido à subjetividade dos analistas; e Produtividade - as categorias serão produtivas se os resultados forem férteis em inferências, em hipóteses novas, em dados exatos.

Vale salientar que a definição de categorias teve em mente a ideia de formar Coleção ${ }^{7}$, não apenas de reunir unidades avulsas de fotografias. A reunião por categorias possibilita estudar o conjunto valendo-se da narrativa fotográfica. Nesse sentido, "as categorias são rubricas ou classes, as quais reúnem um grupo de elementos (...) sob um título genérico, agrupamento esse efetuado em razão das características comuns destes elementos" (BARDIN, 2011, p. 147).

O objetivo foi inicialmente criar categorias gerais, onde serão inseridos novos elementos à medida que haja os desdobramentos naturais advindos da implantação e obtenção de novas imagens. A seguir, elencam-se as categorias e seus respectivos significados:

Quadro 1 - Categorias e seus significados.

\begin{tabular}{|c|l|}
\hline CIENTÍFICO & $\begin{array}{l}\text { Unidades de significação que evidenciam formação acadêmico-profissional, como } \\
\text { pesquisas, atividades dos laboratórios, biotérios etc. }\end{array}$ \\
\hline SOCIAL & $\begin{array}{l}\text { Unidades de significação que tratam de eventos socioinstitucionais, como projetos } \\
\text { de extensão, festas, eventos anuais de socialização entre funcionários, docentes e } \\
\text { discentes; lazer e religiosidade. }\end{array}$ \\
\hline ESTRUTURA & $\begin{array}{l}\text { Reúnem-se as unidades de significação que representam questões físicas, de } \\
\text { funcionamento do Centro, como segurança, espaço, limpeza, acessibilidade, entre } \\
\text { outros. }\end{array}$ \\
\hline POLÍTICA & $\begin{array}{l}\text { Visitas de governantes locais e externos, reuniões administrativas com políticos, } \\
\text { reitor e alto staff. }\end{array}$ \\
\hline RETRATO & Retratos dos técnicos administrativos e docentes. \\
\hline
\end{tabular}

Fonte: Elaborado pelos autores.

$\mathrm{Na}$ etapa que concerne à catalogação se tomou por referência o formato bibliográfico MARC 21 (utilizado pelo Sistema de Bibliotecas da UFPE por meio do catálogo Pergamum) e o padrão de metadados Dublin Core, que é o utilizado no DSpace.

Por ser um formato utilizado no Sistema Integrado de Bibliotecas da UFPE e nacionalmente por grandes instituições de ensino, acrescentou-se um tratamento específico quanto à fotografia na construção da memória com o acréscimo do campo para inserção da

\footnotetext{
${ }^{7}$ Coleção como um todo orgânico, uma unidade, onde cada elemento tem sentido individual e coletivo (PAVÃO, 1997).
}

InCID: R. Ci. Inf. e Doc., Ribeirão Preto, v. 7, n. 1, p. 90-110, mar./ago. 2016. 
Narrativa (de um agente externo - não catalogador - que esteja no contexto de vida do CAV, seja como funcionário, aluno, egresso ou discente) para um fazer memorial.

O acervo fotográfico digital do CAV se traduz em registros individuais de funcionários e alunos, encontrando-se em boa parte disperso. Já iniciado, portanto, o processo de agrupamento contabiliza 1.420 fotografias digitais (até julho de 2014), distribuídas anualmente da seguinte forma: 2010 - 166 registros, 2011 - 184 registros, 2012 - 498 registros, 2013 - 493 registros e 2014 - 79 registros. Os registros revelam as atividades de rotina da Biblioteca como treinamentos, lançamentos de livros, reuniões, espaço físico etc., e quanto ao Centro, algumas atividades comemorativas e o espaço físico de modo geral. Pela abrangência da fotografia no cotidiano humano e pelas funcionalidades da era digital (rápida produção, edição e revisão; distribuição mundial; solução para o armazenamento em longo prazo), o acervo já começa sua concepção em formato digital. A intenção é que reflita a história da instituição, onde se possa conhecer todo o processo que permeia as questões administrativas, a gerência estrutural e de pessoas, as transformações ocorridas em quase nove anos de atividades, que são frutos do projeto de reestruturação do ensino superior público, em resposta à sociedade pelo investimento público.

Nesse sentido, os metadados propostos nesse estudo estão discriminados a seguir:

Quadro 2 - Metadados para a descrição de fotografias digitais visando a construção da memória institucional.

\begin{tabular}{|c|l|}
\hline $\begin{array}{c}\text { AUTOR / } \\
\text { FOTÓGRAFO }\end{array}$ & Dados de autoria que devem conter nome completo e pseudônimo, se houver. \\
\hline TITULO & Elemento criado pelo indexador quando não vier indicado pelo autor. \\
\hline LOCAL E ANO & Local e ano em que a imagem foi feita. \\
\hline DADOS TÉCNICOS & Pode ser o EXIF, encontrados em "Propriedades". \\
\hline PALAVRAS- & $\begin{array}{l}\text { Elemento criado pelo indexador, que deve trazer, de forma concisa, } \\
\text { informações relevantes sobre o contexto da fotografia que possam situar } \\
\text { pessoas no tempo e no espaço, sendo o mais específico possível. }\end{array}$ \\
CHAVE & $\begin{array}{l}\text { Palavras representativas do conteúdo da fotografia que devem ser escolhidas, } \\
\text { preferencialmente, em vocabulário controlado. Orienta-se a utilização de no } \\
\text { mínimo três (03) e no máximo cinco (05). }\end{array}$ \\
\hline CATEGORIA & Criada pelos autores da pesquisa, que consta em lista específica para consulta. \\
\hline NARRADOR 1 & $\begin{array}{l}\text { Dados sobre o narrador (nome completo, profissão e posição dentro da } \\
\text { instituição). }\end{array}$ \\
\hline NARRATIVA 1 & Conforme informado pelo Narrador 1. \\
\hline NARRADOR 2 & $\begin{array}{l}\text { Dados sobre o narrador (nome completo, profissão e cargo dentro da } \\
\text { Instituição). }\end{array}$ \\
\hline NARRATIVA 2 & Conforme informado pelo narrador. \\
\hline NOTAS & Acréscimos relevantes que não couberam nos itens anteriores. \\
\hline
\end{tabular}

Fonte: Elaborado pelos autores.

InCID: R. Ci. Inf. e Doc., Ribeirão Preto, v. 7, n. 1, p. 90-110, mar./ago. 2016. 
Posto isso, após a criação dos metadados para o acervo fotográfico do CAV, apresentam-se, a seguir, dois exemplos, onde constam os campos especificados devidamente preenchidos e sua contribuição para a memória institucional.

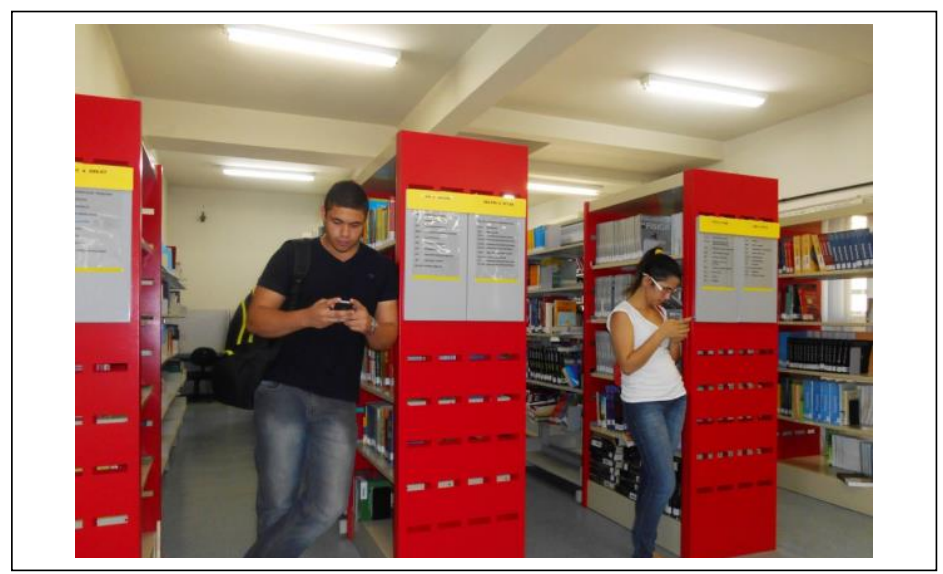

Figura 1 - Exemplo de representação de fotografia no CAV. Fonte: Mendonça (2015)

Quadro 3 - Primeiro exemplo dos metadados para descrição de fotografias digitais visando à memória institucional

\begin{tabular}{|c|l|}
\hline AUTOR / FOTÓGRAFO & Roseane Souza de Mendonça (Roseane Souza) \\
\hline TÍTULO & Internet remota \\
\hline LOCAL E ANO & Vitória de Santo Antão, 2014. \\
\hline DADOS TÉCNICOS & JPEG - Colorida \\
& Câmera compacta Nikon Coolpix S3500V1.0 \\
& Dimensão 5152 x 3864px; \\
& Tamanho 7,72MB; \\
& 300dpi \\
\hline RESUMO & A internet no Centro para trabalhar era de acesso remoto (dependia do \\
& Campus Recife) e a wi-fi de difícil acesso, quase impossível. \\
\hline PALAVRAS-CHAVE & Wi-fi; Problemas; Acesso. \\
\hline CATEGORIA & Estrutura \\
\hline NARRADOR 1 & Giane da Paz Ferreira Silva \\
& Bibliotecária \\
& Coordenadora da BIB-CAV \\
\hline NARRATIVA 1 & "Ao ver essa foto me vem à mente a necessidade e dependência da \\
& rede que a sociedade enfrenta atualmente. Nesse momento as estantes \\
& e as coleções impressas são meros instrumentos de apoio para facilitar \\
& a comunicação com o virtual. \\
& Este foi um momento de crise de acesso à rede vivido no CAV em \\
& 2014, a conexão à internet estava inviável e o sinal só era possível em \\
alguns lugares, o que culminou com a reestruturação da rede, \\
\\
resultando na troca de equipamentos e aumento da velocidade da \\
rede.” \\
\hline & $\begin{array}{l}\text { Foto capturada em 14/04/2014 com ISO 200, abertura de diafragma } \\
\text { f3.4, velocidade do obturador 1/25s, distância focal de 5mm }\end{array}$ \\
\hline
\end{tabular}

Fonte: Elaborado pelos autores. 


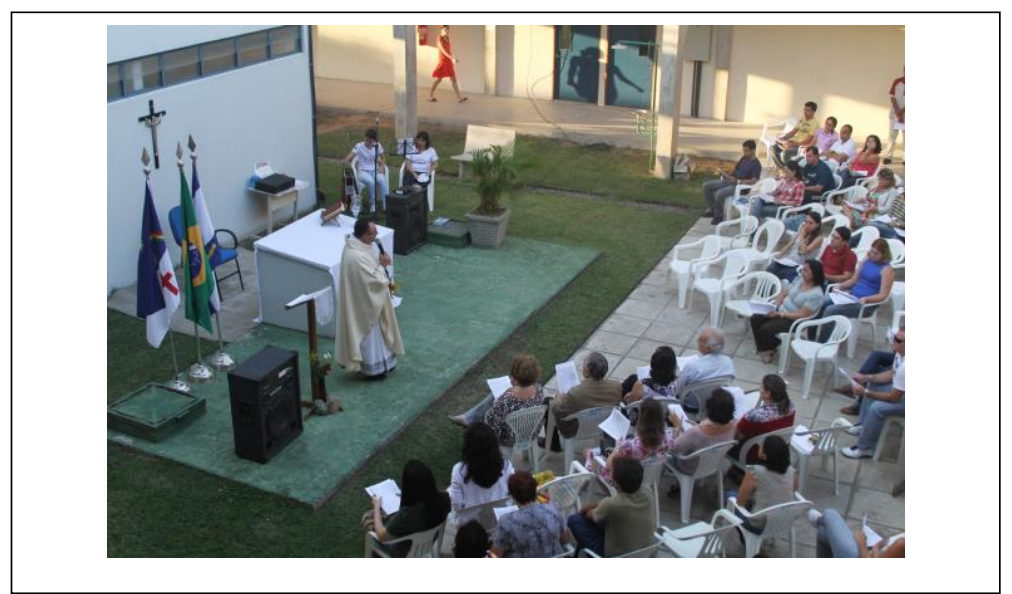

Figura 2 - Exemplo de representação de fotografia no CAV.

Fonte: Mendonça (2015).

Quadro 4 - Segundo exemplo dos metadados para descrição de fotografias digitais visando à memória institucional

\begin{tabular}{|c|c|}
\hline $\begin{array}{c}\text { AUTOR / } \\
\text { FOTÓGRAFO }\end{array}$ & Roseane Souza de Mendonça (Roseane Souza) \\
\hline TÍTULO & Missa de 5 anos \\
\hline LOCAL E ANO & Vitória de Santo Antão, 2011. \\
\hline DADOS TÉCNICOS & $\begin{array}{l}\text { JPEG - Colorida } \\
\text { Câmera Canon EOS 7D; } \\
\text { Dimensão } 5184 \text { x 3456px; } \\
\text { Tamanho 7,15MB; } \\
\text { 72dpi }\end{array}$ \\
\hline RESUMO & - \\
\hline $\begin{array}{l}\text { PALAVRAS- } \\
\text { CHAVE }\end{array}$ & Religião; Missa comemorativa; 5 anos. \\
\hline CATEGORIA & Social \\
\hline NARRADOR 1 & $\begin{array}{l}\text { Giane da Paz Ferreira Silva } \\
\text { Bibliotecária } \\
\text { Coordenadora da BIB-CAV }\end{array}$ \\
\hline NARRATIVA 1 & $\begin{array}{l}\text { "Penso na dificuldade de inserir a presença de Deus no meio laico como é a } \\
\text { Universidade. Significa religiosidade na missa dos cinco anos do CAV na } \\
\text { busca e desafio de dar lugar ao sagrado. } \\
\text { Essa missa ocorreu em } 2011 \text { e foi em ação de graças pelas conquistas de } \\
\text { construção dos anexos e novos prédios do CAV." }\end{array}$ \\
\hline NOTAS & $\begin{array}{l}\text { Captura em 30/08/2011 com ISO } 400 \text {, abertura de diafragma f6.3, velocidade } \\
\text { do obturador } 1 / 125 \mathrm{~s} \text {, distância focal } 28 \mathrm{~mm} \text { sem flash, exposição manual, } \\
\text { balanço de branco automático, representação de cores sRGB. }\end{array}$ \\
\hline
\end{tabular}

Fonte: Elaborado pelos autores. 


\section{Considerações finais}

Identificou-se que a construção da memória institucional é um desafio de considerável proporção. O CAV ainda está em franca consolidação passando por modificações estruturais de espaço físico, bem como a inclusão de novos cursos. Perceber o impacto de sua chegada ao interior do estado de Pernambuco com as mudanças causadas na vida das pessoas e da região, e tentar deixar atestado isso por meio das fotografias serão desafios permanentes.

Quanto à seleção das fotografias e criação das categorias, observou-se a necessidade de despender esforços conjuntos para entender um Sistema de Informação (SI) e conhecer as diretrizes que os rege.

Na representação da informação e do conhecimento percebeu-se que há um padrão a ser seguido, em contradição à ideia individual de conhecimento, mas que tem sido necessário para depurar e tornar disponível a informação gerada e que circula globalmente. Sendo assim, os profissionais da informação vivem em terreno minado; precisam dotar-se de uma gama de habilidades intelectuais e cognitivas para conseguir disponibilizar a informação de forma mais abrangente possível, mas são enquadrados a reduzir o conhecimento ao descrevê-lo em um sistema de informação. Por ser transdisciplinar, a CI cria intercessão com várias áreas do saber, mas carece de uma receptividade aos processos interpretativos.

Quanto à questão de construção da memória institucional a partir das fotografias, entendeu-se que não pode ser uma vontade isolada; trata-se de uma construção coletiva. Fazêla ou a reativar por meio da narrativa parece quase impossível diante da falta de comunicação pessoal na acelerada vida moderna, que cada vez mais tem sido deixada de lado em tempos de redes sociais, whatsApp, twitter e tantos outros. Por tudo isso, a pesquisa aqui desenvolvida não é conclusiva; trata-se de um processo que não é imediato e que envolve consecução em longo prazo, principalmente, quanto ao tempo para obtenção das narrativas.

A fotografia estampa a vida humana cotidianamente, permeia o imaginário social, induz comportamentos, direciona o olhar e molda o mundo ao nosso redor. Ao se constituir em objeto de estudo pela CI passa a ser tratada como documento e luta contra o aprisionamento descritivo; eis mais uma contradição. Muito tem sido criado para análise e descrição de fotografias em SI, contudo, tem-se podado a capacidade narrativa, tão essencial para se "fazer" memória. 
Concluiu-se que o estudo é inovador quanto à descrição em sistemas de informação, o que implica na aceitação de novos metadados e no saber específico na leitura de imagens. Acredita-se que a narrativa abre novas possibilidades na organização e representação da informação e do conhecimento visando ao fazer memorial e que é necessária flexibilização nos sistemas de informação para abraçar os processos interpretativos.

\section{Referências}

ARAGÃO, J. História da Vitória de Santo Antão (1843-1982). Recife: Centro de Estudos de História Municipal, 1983. 384p.

AUMONT, J. A imagem. 13.ed. Campinas: Papirus, 2008. 317p.

BARDIN, L. Análise de conteúdo. São Paulo: Edições 70, 2011. 279p.

BAURET, G. A fotografia: história, estilos, tendências, aplicações. Lisboa: Edições 70, 2010. 132p.

BERNARDES, D. A. M.; PEREIRA, J. M. Quando a cidade era universitária: a geografia da Univer-cidade do Recife antes da construção do campus da UFPE. Estudos Universitários: revista de cultura, Recife, v. 27, n. 8, p.17-25, ago. 2011.

BRASIL. Decreto-Lei no 9.388, de 20 de junho de 1946. Cria a Universidade do Recife e dá outras providências. Diário Oficial [da] República Federativa do Brasil, Poder Executivo, Brasília, DF, 28 jun. 1946. Seção 1, p.9615. Disponível em:

<http://www2.camara.leg.br/legin/fed/declei/1940-1949/decreto-lei-9388-20-junho-1946417645-publicacaooriginal-1-pe.html>. Acesso em: 01 out. 2014.

BRIENEN, R. P. Albert Eckhout: visões do paraíso selvagem: obra completa. Rio de Janeiro: Capivara, 2010. 432 p.

BUCCERONI, C.; PINHEIRO, L. V. R. A imagem fotográfica como documento: desideratos de Otlet. In: ENCONTRO NACIONAL DE PESQUISA EM PÓS-GRADUAÇÃO EM CIÊNCIA DA INFORMAÇÃO, 10., 2009, João Pessoa. Anais eletrônicos... João Pessoa: [s.n.], 2009. p.127-142.

CAPURRO, R.; HJORLAND, B. O conceito de informação. Perspectivas em Ciência da Informação, Belo Horizonte, v. 12, n.1, p.148-207, jan./abr. 2007.

CARDOSO, A. M. P. Retomando possibilidades conceituais: uma contribuição à sistematização do campo da informação social. Revista da Escola de Biblioteconomia da UFMG, Belo Horizonte, v. 23, n. 2, p. 107-114, jul./dez. 1994.

CHAUÍ, M. Convite à filosofia. 13.ed. São Paulo: Ática, 2009. 424 p.

GARDNER, H. Estruturas da mente: a teoria das inteligências múltiplas. Porto Alegre: Artes Médicas, 1994. 340p.

GIL, A. C. Métodos e técnicas de pesquisa social. 6. ed. São Paulo: Atlas, 2008. 200 p. 
GNOLI, C. Metadata about what?: distinguishing between ontic, epistemic, and documental dimensions in Knowledge Organization. Knowledge Organization, v. 39, n. 4, p. 268-275, 2012.

HOLANDA, L. Memória: multiplicidade e permanência. IRIS, Recife, v.1, n.1, p.17-25, jul./dez. 2012.

KOSSOY, B. Fotografia \& história. 2.ed. rev. Cotia: Ateliê Editorial, 2001. 163 p.

LANGDON, E. J. A fixação da narrativa: do mito para a poética de literatura oral. Horizontes Antropológicos, Porto Alegre, v. 5, n. 12, p. 13-36, dez. 1999.

LE COADIC, Y. F. A Ciência da Informação. 2.ed. Brasília: Briquet de Lemos, 2004.

MANINI, M. P. Aspectos informacionais do tratamento de documentos fotográficos tradicionais e digitais. In: FREIRE, G. H. A. (Org.). E-Book do Encontro Nacional da Associação Nacional de Pesquisa em Ciência da Informação. João Pessoa: Ideia: Universitária, 2009. 1 Cd-rom.

MENDONÇA, R. S. A organização documental das fotografias do CAV-UFPE e sua contribuição para a memória institucional. 2015. 99 f. Dissertação (Mestrado em Ciência da Informação) - Universidade Federal de Pernambuco, Recife.

MORENO, N. A.; LOPES, M. A.; DI CHIARA, I. G. A contribuição da preservação de documentos e a (re) construção da memória. Biblionline, João Pessoa, v. 7, n. 2, p. 3-11, 2011.

PAVÃO, L. Conservação de colecções de fotografia. Lisboa: Dinalivro, 1997. 356 p.

POLLAK, M. Memória e identidade social. Estudos Históricos, Rio de Janeiro, v. 5, n. 10, p. 200-212, 1992.

RICHARDSON, R. J. Pesquisa social: métodos e técnicas. 3. ed. rev. ampl. São Paulo: Atlas, 2012. 334 p. Disponível em: <https://pt.scribd.com/doc/226198537/01-Richardson-PesquisaSocial-MCtodos-e-TCcnicas-pdf-PdfCompressor-643562>. Acesso em: 21 jan. 2015.

SANTAELLA, L.; NÖTH, W. Imagem: cognição, semiótica, mídia. São Paulo: Iluminuras, 2010. 222p.

SMIT, J. W. A representação da imagem. INFORMARE: Cadernos do Programa de PósGraduação em Ciência da Informação, Rio de Janeiro, v. 2, n. 2, p. 28-36, jul./dez. 1996.

TACCA, F. Imagem fotográfica: aparelho, representação e significação. Psicologia \& Sociedade, v. 17, n. 3, p. 9-17, set./dez. 2005.

THIESEN, I. Memória institucional. João Pessoa: Ed. da UFPB, 2013. 310 p.

UNIVERSIDADE. In: DICIONÁRIO Priberam da Língua Portuguesa. Lisboa: Priberam Informática, 2013. Disponível em: 〈http://www.priberam.pt/DLPO/universidade>. Acesso em: 08 set. 2014.

WANDERLEY, L. E. W. O que é universidade. 9. ed. São Paulo: Brasiliense, 1994. 83 p. 